\title{
Effect of previous scorpion sting on the efficacy of spinal anesthesia - A case control study
}

\author{
Kosam $D^{1}$, Nigam $R^{2}$, Murthy $M^{3}$, Debbarma $M^{4}$, Chatterjee $S^{5}$ \\ ${ }^{1}$ Dr Durga Kosam, Assistant Professor, ${ }^{2}$ Dr Rakesh Nigam, Associate Professor, ${ }^{3}$ Dr Madhumita Murthy, Associate \\ Professor, ${ }^{4}$ Dr Miltan Debbarma, Assistant Professor, ${ }^{5}$ Dr Sudarshana Chatterjee, Professor. All are affiliated with \\ Department of Anesthesiology and Critical Care, Chhattisgarh Institute of Medical Sciences (CIMS), Bilaspur, \\ Chhattisgarh, CG, India.
}

Address for Correspondence: Dr. Durga Kosam, Email : kosamdurga@gmail.com

\begin{abstract}
Background: Failure/delayed effect of spinal anesthesia were noted in several patients with past history of scorpion sting during routine practice. Scorpion venom is known to delay the activation of sodium neuronal channels. Local anesthetic agents also act through the sodium channels. Therefore this study was conducted to test the association of scorpion sting with failure/resistance to effect of spinal anesthesia. Methods: 40 patients in the age range of 18-80 years were divided into two equal groups. Group 1 with past history of one or multiple scorpion stings and group 2 with no such history. The anaesthetic management was identical i.e. subarachnoid block with $3.5 \mathrm{ml}$. 0.5\% Bupivacaine heavy. The onset of sensory and motor block was noted. Peaks of sensory and motor blocks were also observed. Sensory block was assessed by pin prick method and motor block by Bromage scale. After waiting for $20 \mathrm{~min}$, general anesthesia was administered if the block was inadequate. Results: The time of onset of sensory and motor block as well as the time for the peak of sensory and motor blocks was significantly prolonged in scorpion sting group. 5 patients had failed sensory and motor block. All the patients in control group had adequate subarachnoid block. Conclusion: There is a direct association between previous scorpion sting and development of resistance to the effect of spinal anesthesia.
\end{abstract}

Keywords: Motor block, Scorpion sting, Sensory block, Sodium channel, Spinal anesthesia,

\section{Introduction}

In India two types of poisonous species of scorpion are important - small red Buthus tamulus and the large black Palamneus gravimanus. Buthus tamulus is more toxic. Mesobuthus tamulus (the Indian red scorpion) is the most lethal amongst all poisonous species of scorpions in India [1].

In our region scorpion stings are common. The scorpion venom contains neurotoxins that block the sodium channels (beta-toxins). Delayed activation of sodium neuronal channels by the venom causes massive release of endogenous catecholamines into the circulation resulting in clinical manifestations and complications of scorpion sting [2].

Spinal anesthesia is a common anaesthetic technique

\footnotetext{
Manuscript received: $4^{\text {th }}$ Aug 2015

Reviewed: $19^{\text {th }}$ Aug 2015

Author Corrected: $27^{\text {th }}$ Aug 2015

Accepted for Publication: $8^{\text {th }}$ Sept 2015
}

used for various surgical procedures. Failure of subarachnoid block may occur even in expert hands. Causes of failure of spinal anesthesia may be poor patient positioning, incorrect insertion of spinal needle, spinal abnormalities, obesity, errors in drug injection, inaccurate dose of drug, misplaced injection, inadequate intra thecal spread, inadequate drug action, local anaesthetic resistance etc [3].

Local anesthetics administered by spinal anesthesia acts via sodium channels. Mutations of sodium channel may be responsible for resistance to local anesthetic agents [4]. Scorpion neurotoxin also exerts its clinical manifestations through sodium channel blockade.

In view of high prevalence of scorpion sting in our region and observation of failure of spinal anesthesia in patients with history of scorpion stings in routine practice, the present study was planned. The aim of this study was to compare the efficacy of spinal anesthesia 
in patients with previous scorpion bites and in patients with no such history.

\section{Material and Methods}

Study setting and design: This was a case control study of 40 patients admitted for elective surgery under spinal anesthesia from January 2015 to June 2015 at Chhattisgarh Institute of Medical Sciences Bilaspur (C.G.). 20 patients with previous history of one or more scorpion stings comprised the case group (Group 1). 20 patients with no history of scorpion sting undergoing surgery under spinal anesthesia comprised the control group (Group 2).

Study subjects: 40 patients with age ranging from 18 to 80 years of both sex and American Society of Anesthesiologists (ASA) physical status I to III were included in the study [5]. All patients were admitted for planned surgery under spinal anesthesia. Informed and written consent was obtained for the surgery and anesthesia.

20 patients with history of one or more scorpion bites undergoing spinal anaesthesia comprised the case group (Group 1). 20 patients with no history of scorpion sting undergoing surgery under spinal anaesthesia comprised the control group (Group 2).

All patients were pre-operatively assessed and scheduled to undergo various types of elective surgeries under spinal anaesthesia. Patients were preloaded with $1000 \mathrm{ml}$ of RL solution, placed in lateral position and space between 3rd and 4th lumbar spine was identified and marked. After taking all aseptic measures lumbar puncture was done with 24 - 25 gauge pencil point spinal needle and hyperbaric Bupivacaine $0.5 \%, 3.5 \mathrm{ml}$ was administered .Immediately after injection of Bupivacaine patient was placed in supine position. Electrocardiography, $\mathrm{SpO}$, heart rate and non invasive blood pressure monitoring was done during surgery.

In the operating room the following parameters were recorded: T0-time of the spinal injection, $\mathrm{T} 1$-onset of the sensory block, T2-onset of motor block, T3-peak of sensory block and T4-peak of motor block. If after a 20 min period the block was not adequate, general anaesthesia was administered. At the end of surgery, all patients were transferred to Intensive Care Unit for post-operative monitoring during the first $24 \mathrm{~h}$.

Sensory block was assessed by pin prick with a 24 gauge hypodermic needle. The onset of sensory block was defined as the time when the patient could not feel the pain. Motor block was assessed with Bromage scale [6] as follows-

\begin{tabular}{|l|l|}
\hline Grade of motor block & Features \\
\hline Grade 3 & Complete block, unable to move feet or knees. \\
\hline Grade 2 & Almost complete, able to move feet only or plantar flexion of the big toe. \\
\hline Grade 1 & Partial, just able to flex/move knees. \\
\hline Grade 0 & None, full flexion of knees, hip and feet. \\
\hline
\end{tabular}

The onset of motor block was considered as the time when patient could not flex the hip. The time of peak sensory and peak motor levels were considered when the maximum/upper most level of the block was achieved and there was no further progression of either the sensory or motor blockade, above that level. The block was considered to be adequate when level of sensory/motor block of up to T6-T8 was achieved. If after a 20 min period the block was not adequate, general anaesthesia was administered.

Statistical Analysis of the data and application of various statistical tests were carried out with the help of Statistical Package for Social Services (SPSS version 11.5). Mean, summation, percentage and frequency distribution were used where applicable. Mean and proportion were compared using student t-test. P value $<0.05$ was considered as statistically significant.

\section{Results}

Patient characteristics : The baseline characteristics of patients in group 1 (scorpion sting group) and group 2 (control group) were comparable. Maximum number of patients was in the age group of 25 to 44 years (mean age $=39.65 \pm 10.74$ years). There was male preponderance in both groups. Most of the patients undergoing surgery belonged to ASA (American Society of Anesthesiologist) grade 1 classification (Table 1). 
Table 1: Demographic profile of patients in two groups

\begin{tabular}{|l|l|l|l|}
\hline Patient characteristics & Group 1 (N=20) & Group 2 (N=20) & Total (N=40) \\
\hline Age in years & & $1(5 \%)$ & $3(7.5 \%)$ \\
25 years 34 years & $2(10 \%)$ & $5(25 \%)$ & $12(30 \%)$ \\
$35-44$ years & $7(35 \%)$ & $7(35 \%)$ & $13(32.5 \%)$ \\
$45-54$ years & $6(30 \%)$ & $4(20 \%)$ & $7(17.5 \%)$ \\
$\geq 55$ years & $3(15 \%)$ & $3(15 \%)$ & $5(12.5 \%)$ \\
\hline Age in years $($ mean \pm SD) & $38.35 \pm 10.82$ & $40.95 \pm 10.77$ & $39.65 \pm 10.74$ \\
\hline $\begin{array}{l}\text { Gender } \\
\text { Male }\end{array}$ & $12(60 \%)$ & $13(65 \%)$ & $25(62.5 \%)$ \\
Female & $8(40 \%)$ & $7(35 \%)$ & $15(37.5 \%)$ \\
\hline $\begin{array}{l}\text { ASA Grade } \\
1\end{array}$ & 12 & 14 & 26 \\
2 & 0 & 0 & 14 \\
\hline
\end{tabular}

Number of scorpion bites: Most of the patients (17) had only one scorpion bite in the past. 2 patients gave history of 2 scorpion bites in the past whereas history of $>2$ scorpion bites was reported by only 1 patient (Table 2 ).

Table 2: Scorpion bites in Group 1

\begin{tabular}{|l|l|l|}
\hline Number of bites & Number of patients & Percentage \\
\hline 1 & 17 & 85 \\
\hline 2 & 2 & 10 \\
\hline$>2$ & 1 & 5 \\
\hline Total & $\mathbf{2 0}$ & $\mathbf{1 0 0}$ \\
\hline
\end{tabular}

1. Duration of scorpion bite : $7 / 20$ patients were stung by scorpion within the past 6 months. $7 / 20$ patients had history of scorpion bite 6-12 months back whereas 6/20 patients reported being bitten by scorpion > 12 months back (Table 3).

Table 3: Duration of scorpion bite

\begin{tabular}{|l|l|l|}
\hline Duration of scorpion bite & Number of patients & Percentage \\
\hline$<6$ months & 7 & 35 \\
\hline $6-12$ months & 7 & 35 \\
\hline$>12$ months & 6 & 30 \\
\hline
\end{tabular}

2. Effect of scorpion sting on subarachnoid block: $4 / 20$ (20\%) patients with past history of scorpion sting had adequate subarachnoid block. Complete failure of subarachnoid block was documented in 5/20 patients necessitating administration of general anesthesia. 11/20 patients had delayed sensory/motor block (Pie chart 1). All patients with no history of scorpion bite had adequate subarachnoid block.

Pie Chart 1: Effect of scorpion sting on subarachnoid block 


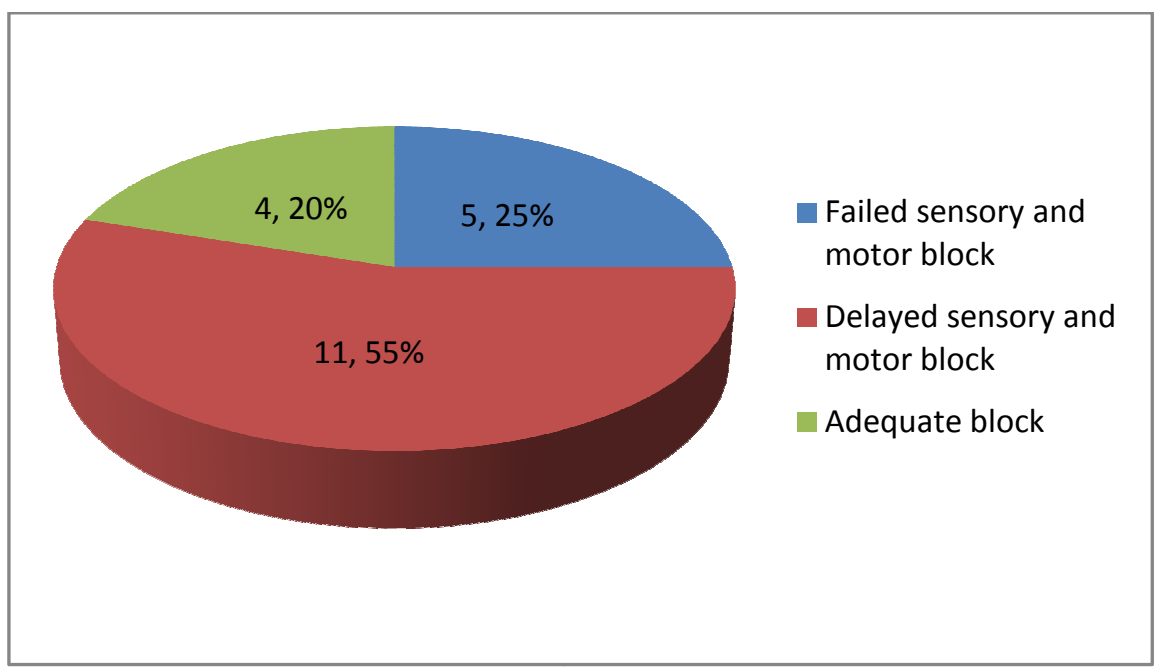

1. Effect of duration of scorpion bite on efficacy of spinal anesthesia: Complete failure of spinal anesthesia requiring administration of general anesthesia was documented only in those patients who had previous history of scorpion bite $<6$ months back. Patients who were bitten by scorpion $>6$ months back did not show failure of spinal anesthesia. Adequate subarachnoid block was noted in those patients who had past history of scorpion sting > 12 months back. Thus the effect of scorpion sting on spinal anesthesia is more pronounced in recent bites and gradually wanes off after 12 months. (Table 4).

Table 4: Association of duration of scorpion bite on efficacy of subarachnoid block

\begin{tabular}{|l|l|l|l|l|}
\hline $\begin{array}{l}\text { Duration of } \\
\text { scorpion bite }\end{array}$ & $\begin{array}{l}\text { Adequate block } \\
\mathbf{N}, \%\end{array}$ & $\begin{array}{l}\text { Failed block } \\
\text { N, \% }\end{array}$ & $\begin{array}{l}\text { Delayed sensory/motor } \\
\text { block N, \% }\end{array}$ & Total \\
\hline$<6$ months & 0 & $5(71.4 \%)$ & $2(28.6 \%)$ & 7 \\
\hline $6-12$ months & 0 & 0 & $7(100 \%)$ & 7 \\
\hline$>12$ months & $4(66.7 \%)$ & 0 & $2(33.3 \%)$ & 6 \\
\hline Total & 4 & 5 & 11 & 20 \\
\hline
\end{tabular}

1. Effect of scorpion sting on onset and peak of sensory and motor block-

Onset of sensory and motor block in group 1 (scorpion sting group) was significantly prolonged as compared to group 2 (control group) $(\mathrm{p}=0.001, \mathrm{p}=0.000)$. The peak of sensory and motor block was also significantly prolonged in scorpion sting group ( $\mathrm{p}=0.000)$ (Table 5). This shows that efficacy of spinal anesthesia is significantly reduced in patients with past history of scorpion sting.

Table 5: Onset of sensory and motor block, time to peak sensory and motor block

\begin{tabular}{|l|l|l|l|l|}
\hline & Group 1 & Group 2 & Total & p value \\
\hline $\begin{array}{l}\text { Onset of sensory block } \\
(\mathrm{min})\end{array}$ & $3.39 \pm 1.21$ & $1.80 \pm 0.653$ & $2.48 \pm 1.21$ & $\mathrm{p}=0.001$ \\
\hline Onset of motor block (min) & $4.23 \pm 0.727$ & $2.26 \pm 0.520$ & $3.10 \pm 1.16$ & $\mathrm{p}=0.000$ \\
\hline Peak of sensory block $(\mathrm{min})$ & $7.08 \pm 0.68$ & $3.82 \pm 0.589$ & $5.22 \pm 1.74$ & $\mathrm{p}=0.000$ \\
\hline Peak of motor block (min) & $8.36 \pm 0.74$ & $4.43 \pm 0.56$ & $6.35 \pm 1.95$ & $\mathrm{p}=0.000$ \\
\hline
\end{tabular}

\section{Discussion}

Spinal anesthesia failure is an uncommon phenomenon. This may be erroneously attributed to poor technique/ less skill on the part of the anesthesiologist. It might not be the mistake of anesthesiologist but some unknown factors might be responsible for resistance/failure of subarachnoid block. 
The reported incidence of spinal anesthesia failure is $0.72 \%-16 \%$ [7]. Causes of spinal anesthesia failure are [8]-

1) Successfully injected drug that are maldistributed relative to the needs of the planned surgery.

2) Unrecognized failed injection of drug, partial or total.

3) Technical failure to enter the subarachnoid space, with no drug injection.

4) Drug errors, i.e. wrong drugs and inappropriate additives.

5) Local anesthetic resistance.

6) Pseudo block failure due to excessive expectations for speed of block onset.

7) Subdural injection of a spinal dose is conceptually a possible cause of spinal block failure, but has never been reported, recognized or studied in this context of smallvolume injections.

In our study spinal anesthesia failure and delayed effect was documented in significant number of patients with past history of scorpion sting. The Anesthetists administering spinal anesthesia were skilled and experienced. Thus the possibility of technical failure, drug error and other factors which could lead to spinal anesthesia failure were negligible. Scorpion sting in the recent past was the most likely explanation for this phenomenon.

Scorpion sting is common in tropical countries. Scorpions are found in crevices of dwellings, underground burrows, under logs or debris, paddy husk, sugarcane fields, coconut and banana plantations. Maximum incidence of scorpion bite occurs in summer and rainy season (breeding season) [9]. Scorpion sting is common in our region because of predominant rural background, rural dwellings, agricultural activities related to paddy, practice of sleeping on floor and not wearing footwear.

Scorpion venom contains neurotoxic proteins. Alpha and Beta toxins act on sodium channels. Scyllatoxin, charybdotoxin and tityus toxin inhibits calcium dependent potassium channels and also causes opening of sodium channels at presynaptic nerve terminals [9].Sodium channels are composed of $\alpha$ and $\beta$ subunits. A subunit has four homologous domains (D 1-4), each containing six transmembrane $\alpha$ helices (S1-S6). S4 segment play a key role in channel activation [10]. Scorpion $\beta$ toxin bind to receptor site 4 of voltage gated sodium channels thereby modifying the activation process of the channel $[11,12]$.

Local anesthetic drugs act by blockage of voltage gated sodium channels. Local anaesthetic action is due to an interaction with the 6th segment of domain four of the alpha subunit (IV-S6). Resistance to local anesthetics may be related to the alpha subunit of the sodium channel and more specifically to the 6th segment of domain four of this subunit [13].

The results of our study show that patients with past history of scorpion bites had inadequate or failed subarachnoid block. There was delay in onset and the peak effect of both sensory and motor blockade in scorpion sting group as compared to patients with no history of scorpion bite. Patients with recent scorpion bites ( $<6$ months) had complete failure of the spinal block requiring administration of general anaesthesia. Patients with scorpion bites > 6 months back demonstrated delayed onset and delayed peak of the sensory block or the motor block or both. Few patients of scorpion bite > 1 year back had adequate subarachnoid block. All patients with no history of scorpion bite had adequate subarachnoid block. Similar result has been documented in a study by Panditrao et al [14].

The possible mechanism of resistance to local anesthetic agent following scorpion sting could be antibody mediated. Scorpion venom due to its antigenic nature may produce an antigen-antibody response. This results in formation of antibodies to scorpion venom. When local anesthetic was administered this circulating antibodies may produce competitive antagonism at sixth segment of domain four of the alpha subunit (IV-S6) of the sodium channels where the local anesthetics are supposed to act [10]

Scorpion bite is common in our country. Still we do not consider past history of scorpion bite as a relevant part of our routine history taking when patient comes for other medical or surgical condition. Keeping in view the results of our study all patients undergoing surgery should be screened for history of scorpion sting. If patients have past history of scorpion bite then anesthesiologist should be prepared for possibility of local anesthesia failure and requirement of general anesthesia.

\section{Conclusion}


Patients with past history of scorpion sting leads to inadequate block or failure of subarachnoid block necessitating conversion to general anesthesia. Anesthesiologists should always ask past history of scorpion sting prior to surgery in all patients in regions where scorpion sting is common.

\section{Funding: Nil}

Conflict of interest: None.

Permission of IRB: Yes

\section{References}

1. Bawaskar HS, Bawaskar

Indian red scorpion envenoming. Indian

PH.

Pediatr. 1998 May-Jun;65(3):383-91.

2. Bawaskar HS, Bawaskar PH. Cardiovascular manifestations of severe scorpion sting in India (review of 34 children).Ann Trop Paediatr. 1991;11(4):381-7.

3. Fettes PD, Jansson JR, Wildsmith JA. Failed spinal anaesthesia: mechanisms, management, and prevention.

$\mathrm{Br} \quad \mathrm{J} \quad$ Anaesth. 2009 Jun;102(6):739-48. doi: 10.1093/bja/aep096. Epub 2009 May 6.

4. Kavlock R, Ting PH. Local anesthetic resistance in a pregnant patient with lumbosacral plexopathy. BMC Anesthesiol. 2004 Jan 16;4(1):1.

5. Haynes SR, Lawler PG. An assessment of the consistency of ASA physical status classification allocation. Anaesthesia. 1995 Mar;50(3):195-9.

6. Graham AC, McClure JH. Quantitative assessment of motor block in labouring women receiving epidural analgesia. Anaesthesia. 2001 May;56(5):470-6.

7.Guinard JP, Carpenter RL, Smith HS. A prospective evaluation of the failure rate of spinal anaesthesia for transurethral prostatic resection. Eur J Anaesthesiol. 1992 Jan;9(1):7-13.

8. Raw RM, Nwaneri ER. Spinal anesthetic block failure due to the hyperbaric nature of the chloroprocaine local anesthetic.Ambul Surg 2010; 16:99- 102.

9. Singh UK, Layland FC, Prasad R, Singh S. Poisoning in children. $4^{\text {th }}$ ed. New Delhi: Jaypee brother's medical publishers (P) Ltd; 2013.

10. Ragsdale DS, McPhee JC, Scheuer T, Catterall WA. Molecular determinants of state-dependent block of $\mathrm{Na}+$ channels by local anesthetics.Science. 1994 Sep 16;265(5179):1724-8.

11. Cestèle S, Scheuer T, Mantegazza M, Rochat H, Catterall WA. Neutralization of gating charges in domain II of the sodium channel alpha subunit enhances voltage-sensor trapping by a beta-scorpion toxin. J Gen Physiol. 2001 Sep;118(3):291-302..

12. Bosmans F, Tytgat J. Voltage-gated sodium channel modulation by scorpion alpha-toxins. Toxicon. 2007 Feb;49(2):142-58. Epub 2006 Sep 28.

13. Batas D, Nejad MR, Prabhu PK. Resistance to local anaesthetics: A case report. Published; 26th January 2007.

Available from:http://www.bja.oxfordjournals.org/cgi/qa-display/ short/brjana_el; 1576. [Last accessed 2015 Aug 20].

14. Panditrao MM , Panditrao MM, Khan MI, Yadav N. Does scorpion bite lead to development of resistance to the effect of local anaesthetics? Indian J Anaesth. 2012 Nov;56(6):575-8. doi: 10.4103/00195049.104582 .

\section{How to cite this article?}

Kosam D, Nigam R, Murthy M, Debbarma M, Chatterjee S. Effect of previous scorpion sting on the efficacy of spinal anesthesia - A case control study. Int J Med Res Rev 2015;3(8):826-831. doi: 10.17511/ijmrr.2015.i8.155. 